\title{
Investigando os motivos para ensinar Ciências às novas gerações
}

\section{Investigating the reasons for teaching science to new generations}

\author{
Larissa Lunardi (larissalunardi18@gmail.com) \\ Universidade Federal da Fronteira Sul (UFFS)
}

Rúbia Emmel (rubia.emmel@iffarroupilha.edu.br)

Instituto Federal Farroupilha (IFFar)

\begin{abstract}
Resumo: Este estudo teve como objetivo analisar o modelo de Investigação-FormaçãoAção em Ciências (IFAC) nos processos de formação docente inicial de Ciências e Biologia e as compreensões sobre os motivos para ensinar Ciências às novas gerações. Esta pesquisa apresenta uma abordagem qualitativa e documental. O instrumento de coleta de dados utilizado foi escritas narrativas realizadas, em diários de formação, por 14 licenciandos matriculados no componente curricular de Prática enquanto Componente Curricular III do $3^{\circ}$ semestre de um curso de Licenciatura em Ciências Biológicas. A perspectiva de análise adotada foi a Análise Textual Discursiva (ATD) elaborada por meio de processos de unitarização, categorização e comunicação. A partir da ATD emergiram três categorias: Ciências e cotidiano; Ciências para preservar o meio ambiente; e Ciências para ser crítico. A partir dessas categorias, percebeu-se que as escritas narrativas permitem aos licenciandos, no movimento de IFAC, a reflexão sobre os motivos para ensinar Ciências, os quais fazem parte da sua constituição docente e que estarão refletidos em suas futuras práticas pedagógicas.
\end{abstract}

Palavras-chave: Ensino de Ciências; formação inicial de professores; professores de Ciências e Biologia.

Abstract: This study aimed to analyze the Research-Training-Action in Science (IFAC) model in the initial teacher education processes in Science and Biology and understandings about the reasons for teaching Science to new generations. This research presents a qualitative and documentary approach. The data collection instrument used was written narratives made in training diaries by 14 undergraduate students enrolled in the curricular component of Practice as Curricular Component III of the 3rd semester of a Biological Sciences Degree course. The perspective of analysis adopted was the Discursive Text Analysis (DTA) elaborated through processes of unitarization, categorization and communication. Three categories emerged from the ATD: Science and everyday life; Sciences to preserve the environment; and Science to be critical. From these categories, it was realized that the narrative writings allow undergraduates, in the IFAC movement, to reflect on the reasons for teaching Sciences, which are part of their teaching constitution and which will be reflected in their future pedagogical practices.

Key words: Science teaching; initial teacher formation; Science and Biology teachers.

Recebido em: 18/01/2021

Aceito em: 24/02/2021 


\section{INTRODUÇÃO}

Este estudo assume, em seu processo, a Investigação-Formação-Ação em Ciências (IFAC), a qual pode se constituir como uma proposta de formação inicial de professores (GÜLLICH, 2012; EMMEL, 2015; BREMM; GÜLLICH, 2020; RADETZKE, 2020). A Investigação-Formação-Ação (IFA) se originou da Investigação-Ação (IA) crítica e/ou emancipatória, essa que tem como premissa básica a pesquisa da própria prática, visando a transformação e melhoria do contexto em que o docente se insere (CONTRERAS, 1994; GÜLLICH, 2012). A IFA considera o valor formativo da reflexão crítica da IA, uma vez que, ao refletir e conceitualizar a experiência profissional, o docente se forma e se constitui como pesquisador (ALARCÃO, 2011). O termo se amplia para IFAC quando o processo de formação é direcionado ao ensino e à aprendizagem de Ciências.

Consideramos, nesta IFAC, a reflexão como categoria formativa na formação inicial de professores, já que seus pressupostos teóricos permitem analisar e repensar a prática docente (ZEICHNER, 2008). Nesse contexto, por meio do processo de escritas narrativas foi possível reconhecer compreensões que envolvem o ensino de Ciências (GASTAL; AVANZI, 2015). Tais perspectivas perpassam a racionalidade técnica e convergem na busca da racionalidade crítica.

Com isso, a autora pós-graduanda realizou a investigação e o estágio de docência no terceiro semestre de um curso de Licenciatura em Ciências Biológicas, em uma Instituição de Ensino Superior localizada na Região Noroeste do estado do Rio Grande do Sul. Essa realização se deu na Prática enquanto Componente Curricular III (PeCC III), componente do curso, e caracterizou a intervenção para que fosse possível o desenvolvimento da IFAC.

Neste processo, os licenciandos escreveram e refletiram sobre as compreensões acerca dos motivos que o docente deve ter em mente para ensinar Ciências às novas gerações. Tais entendimentos deram origem ao ciclo reflexivo que constitui este estudo. A partir da IFAC, realizada na formação inicial de professores de Ciências Biológicas, foi possível analisar as reflexões sobre a constituição docente. Importa ressaltar que as professoras formadoras desta pesquisa assumem-se como pesquisadoras de segunda 
ordem (ELLIOTT, 1990), ou seja, investigadoras de escritas narrativas das histórias e experiências de outros pesquisadores (licenciandos).

Sendo assim, esta pesquisa tem como objetivo analisar as compreensões, desenvolvidas por meio de um processo de IFAC na formação inicial de professores de Ciências e Biologia, de licenciandos acerca dos motivos que os docentes devem ter em mente ao exercer a profissão docente de Ciências. Nesse sentido, a IFAC é aqui alocada por ser um importante processo para a criação de diálogo entre professores em formação inicial, uma vez que suas compreensões sobre os motivos de ensinar Ciências influenciarão suas ações em sala de aula, refletindo no desenvolvimento profissional desses futuros professores.

\section{POR QUE INVESTIGAR OS MOTIVOS PARA ENSINAR CIÊNCIAS?}

Nesta IFAC, acreditamos que pensar sobre os motivos que levam a ensinar Ciências potencializa as reflexões sobre o ensino desse componente curricular. Dessa forma, Chaves (2013) ressalta que "no meio escolar já não é suficiente pensar como ensinar conteúdos das ciências, é fundamental questionar o que e, principalmente, porque ensinar" (p. 126, grifos da autora). A autora continua: "mais do que pensar formas, estratégias eficientes de ensinar, divulgar os produtos da ciência, ao professor cabe questionar, problematizar os processos de produção do conhecimento, o valor social e a ideologia encoberta por pretensa neutralidade dos conteúdos" (CHAVES, 2013, p. 126). Nesse sentido, os motivos para ensinar Ciências fazem parte da sua constituição, por isso, se refletem constantemente na prática do professor.

Preocupada com essas questões, Chaves (2007) realizou uma pesquisa com professores em diferentes espaços de formação (graduação, especialização e mestrado), para compreender 'por que ensinar Ciências às novas gerações?'. Para a autora:

as motivações para se ensinar o conhecimento sistematizado revelam muito da compreensão que temos sobre o papel e o valor que a Ciência desempenha em nossa vida pessoal e na sociedade de modo mais amplo, decorrendo dessa compreensão a forma como educamos em Ciências as novas gerações (CHAVES, 2007, p. 13).

Essa problematização nos faz refletir sobre "o valor que se atribui ao conhecimento sistematizado - seja ele de Ciências ou das demais disciplinas escolares e as razões porque consideramos importante ensiná-lo em detrimento de inúmeros outros saberes existentes" (CHAVES, 2007, p. 13). Dentre os registros das respostas 
dos professores, a autora destaca a de uma participante que percebeu "que sua forma de exercer a docência estava intimamente conectada com a concepção de Ciência que trazia consigo de maneira tácita e inquestionada. Concepção essa que orientava, além da conduta profissional, sua postura como cidadã" (CHAVES, 2007, p. 19).

Dessa forma, percebemos como as compreensões acerca das Ciências e de sua natureza interferem na constituição do cidadão e do professor, afinal, "a educação deve objetivar a formação de sujeitos críticos, reflexivos, propositivos" (CHAVES, 2007, p. 19). Para Chaves (2007):

\begin{abstract}
alfabetizar cientificamente, portanto, envolve incluir no repertório intelectual dos estudantes conhecimentos que lhes possibilitem compreender as múltiplas dimensões (técnica, política, social) que constituem o conhecimento científico e não ensinar palavras, definições soltas que pouco contribuem para a apropriação da linguagem da Ciência, pois não aprenderemos a nos expressar em outra língua, ainda que tragamos na memória todas as palavras de um dicionário de idiomas, é preciso imersão na nova cultura (p. 20).
\end{abstract}

Destarte, a partir dessa imersão, a autora destaca questões importantes sobre como desenvolver esse conhecimento científico:

Do meu ponto de vista é importante e urgente para deixarmos de contribuir, por meio do nosso ensino, com a intolerância para com as múltiplas formas de identidades constituídas no mundo, para efetivamente fomentarmos a participação social nos processos decisórios que envolvem nossa existência, e a qualidade dela, como espécie, cultura, indivíduo, para assumirmos com consciência nossa parcela de responsabilidade pelo presente e pelo futuro das novas gerações, para construirmos uma ciência prudente para uma vida decente (CHAVES, 2013, p. 55).

Desse modo, é preciso desconstruir essa visão de Ciência como conhecimento único e absoluto, para nos aproximarmos dos ideais de igualdade, democracia e justiça que a sociedade necessita; e temos na escola um espaço privilegiado para essa reconstrução (CHAVES, 2007). Para isso, a formação docente precisa ser repensada "de maneira a incluir a reflexão epistemológica que possibilite ao professor conquistar sua autonomia" (CHAVES, 2007, p. 22), promovendo a reflexão sobre os motivos para ensinar Ciências e outras questões que influenciam a prática pedagógica docente.

Assim, corroboramos com Chaves (2013) quando ressalta que "formar professores é, então, promover a formação de intelectuais aptos a produzir e intervir no processo educativo" (p. 126), já que as necessidades formativas docentes envolvem diversas habilidades "que vão desde os usuais domínios de conteúdo e escolha de estratégias de 
Edição Especial: I SSAPEC - Simpósio Sul-Americano de Pesquisa em Ensino de Ciências

ISSN: 2595-4520 Vol. 4, n. 32021

ensino, até a produção de pesquisas sobre seu fazer docente, passando pela seleção, organização de conteúdos, elaboração de recursos e atividades de ensino" (p. 126-127).

Não obstante, acreditamos que, por meio da IFAC e a partir das memórias e compreensões dos licenciandos expressas em suas escritas narrativas nos diários de formação (LUNARDI; EMMEL, 2020b), é possível refletir sobre os conhecimentos (conceituais, atitudinais e procedimentais - o que ensinar?), sobre as metodologias de ensino (como ensinar?) (LUNARDI; EMMEL, 2020a) e os motivos para ensinar ciências (por que ensinar?), este último que será apresentado nesse artigo.

\section{METODOLOGIA}

Esta pesquisa apresenta uma abordagem qualitativa (LÜDKE; ANDRÉ, 1986) e caracteriza-se pela tipologia de pesquisa documental realizada em diários de formação (BOSZCO; ROSA, 2020; PORLÁN; MARTÍN, 1997; EMMEL, 2015). Essa ferramenta é um guia que torna possível a reflexão sobre a prática, além de apresentar muitas vantagens, porque "o seu conteúdo é a construção da experiência vivida, não apenas fatos, mas também sentimentos, e permite a tomada de consciência daquilo que foi objetivo e subjetivo" (GIANOTTO, 2012, p. 19).

As escritas foram produzidas, durante as aulas do Estágio de Docência, por 14 licenciandos matriculados na PeCC III do terceiro semestre do curso de Licenciatura em Ciências Biológicas, de fevereiro a maio de 2020. Os licenciandos consentiram em participar da pesquisa, e por questões éticas foram criados códigos para identificá-los: "L” (licenciando), seguida de numeração em ordem crescente: L1, L2 até L14.

A análise da pesquisa foi realizada por meio dos princípios da Análise Textual Discursiva (ATD) (MORAES; GALIAZZI, 2016), seguindo as etapas de unitarização: em que os textos elaborados foram fragmentados por meio das interpretações e compreensões dos trabalhos, das quais emergiram, assim, unidades de significado (US); categorização: processo em que se estabeleceu relações entre as unidades de significado, agrupando-as de acordo com suas semelhanças semânticas; comunicação: elaboraram-se textos descritivos e interpretativos (metatextos) sobre as categorias constituídas. De acordo com a ATD, as escritas narrativas passam a ser denominadas corpus da pesquisa, e são apresentadas neste estudo em destaque tipográfico itálico. 
A emergência das categorias favoreceu uma maior análise e permitiu observar as temáticas da pesquisa a partir de um cenário reflexivo. Para a tabulação, os dados foram dispostos em planilhas no programa Excel, facilitando a representação, a verificação das relações e as aproximações entre as respostas. As categorias foram, a posteriori, emergindo de acordo com o processo de análise. A elaboração dos dados de pesquisa propiciou a constituição das análises nesta investigação, que tem o objetivo de discutir e problematizar a constituição docente de licenciandos em Ciências Biológicas acerca dos motivos que o professor de Ciências deve ter ao ensinar.

\section{RESULTADOS E DISCUSSÕES}

A problematização que norteou as escritas dos licenciandos e as buscas para a ATD, inspirada pelo artigo de Chaves (2007), "por que ensinar Ciências para as novas gerações?", deu origem a escritas narrativas que apresentam as compreensões dos licenciandos. Essas escritas foram constituídas a partir da sua atuação como alunos de Educação Básica e como futuros professores de Ciências e Biologia.

No artigo citado, Chaves (2007) escreve sobre as respostas dos professores de Educação Básica a esse questionamento e conclui que a Ciência é tratada como a única ou a melhor forma de acesso ao mundo. A autora percebeu que essa visão da Ciência é a predominante na sociedade, e critica o fato do conhecimento científico ser tratado como único, verdadeiro e neutro. Destaca a importância de adicionar os conhecimentos de mundo ao repertório intelectual dos sujeitos, tendo a Ciência como outra ou mais uma forma de ver e interpretar o mundo.

A partir das escritas narrativas dos licenciandos emergiram, por meio da ATD, três categorias: Ciências e cotidiano; Ciências para preservar o meio ambiente; $e$ Ciências para ser crítico. Tais categorias expressam as finalidades e os motivos para ensinar ciências, de acordo com a visão dos futuros professores.

\subsection{Ciências e cotidiano}

A maioria dos licenciandos citou que compreender o mundo, a vida e a realidade que nos cerca são os principais motivos que devem mover o ensino de Ciências. Com isso, a categoria Ciências e cotidiano se constituiu de 13 US que emergiram das narrativas de 12 licenciandos. Abaixo constam alguns exemplos: 
Para que as novas gerações tenham conhecimento da natureza e da sua importância para todos, além de aprender como é o funcionamento do que fazemos parte (L9, 2020).

Para que estes [estudantes] entendam sobre a vida e a realidade na qual estão inseridos, e saibam refletir acerca de seu papel na sociedade em relação à natureza de uma forma geral (L10, 2020).

Ao abordar o papel das Ciências na vida social do indivíduo, sua função e necessidade, Delizoicov e Angotti (1994) defendem que, para o exercício pleno da cidadania, é necessária uma mínima formação na área das Ciências para compreender sua natureza, construção e a sociedade em que vivemos.

Para Selles e Ferreira (2005, p. 50), é no componente curricular de Biologia "que repousa uma parte significativa das expectativas de que os conhecimentos adquiridos na escola possam tanto estabelecer vínculos mais estreitos com a realidade quanto auxiliar na resolução dos inúmeros problemas sociais". Acreditamos que, além da Biologia, o componente curricular de Ciências também tem essa função, principalmente porque pode envolver o cotidiano em grande parte dos conteúdos que são trabalhados em sala de aula.

A partir das ideias de Chassot (2018), sobre a alfabetização científica, compreendemos a importância e a centralidade do professor de Ciências nesse processo, pois os professores podem alfabetizar cientificamente os estudantes para que não apenas consigam fazer uma leitura do mundo, mas para que consigam entender suas necessidades de transformá-lo para melhor. Lembrando que tal leitura não desvaloriza as outras, é apenas mais uma leitura. Nesse processo de alfabetização, ficamos imersos em uma outra cultura, a científica, que abrange o nosso repertório cultural e o deixa mais diverso (CHAVES, 2007). Por isso, contextualizar os conteúdos é fundamental para dar sentido às Ciências. $\mathrm{O}$ contexto em que o aluno está inserido é a causa e a consequência do que ele aprende.

Nesse sentido, Kato e Kawasaki (2011) abordam as relações com as experiências dos alunos, tanto as pessoais, quanto as sociais, com a cidadania e com a realidade como uma das concepções de contextualização do ensino. De acordo com Fracalanza, Amaral e Gouveia (1986), o cotidiano pode estar presente de duas maneiras nos processos de ensino e de aprendizagem: uma delas se preocupa com a aplicação da aprendizagem na solução de problemas práticos da vida do estudante, e a outra utiliza o cotidiano como motivação para o aluno. 
Porém, de acordo com esses autores, são cometidos equívocos que devem ser enfrentados. O primeiro deles é que os conteúdos escolares não devem ter compromisso prioritário com a utilidade imediata, mas devem contribuir para a formação intelectual do sujeito. O segundo equívoco é o de simplesmente utilizar o cotidiano como motivação, sem articular com as demais fases da aprendizagem. Por fim, o terceiro equívoco é a noção de um cotidiano padronizado e estereotipado, como abordado nos livros didáticos, constituindo conceitos, muitas vezes, de cenários irreais e abstratos (FRACALANZA; AMARAL; GOUVEIA, 1986).

\subsection{Ciências para preservar o meio ambiente}

A segunda categoria que emergiu das narrativas se chama Ciências para preservar o meio ambiente. Tal categoria é constituída de quatro US que emergiram das escritas narrativas de quatro licenciandos. Seguem alguns exemplos.

Os conteúdos abordados [em Ciências] são de suma importância, independente da área que o aluno seguir. O conhecimento sobre a vida nos ajuda a amadurecer nosso ponto de vista, bem como nos conscientiza em relação ao meio ambiente, animais e a vida humana (L2, 2020).

Entender como a natureza funciona, sua importância e os cuidados (L3, 2020).

Nesse sentido, "a educação ambiental assume cada vez mais uma função transformadora, na qual a co-responsabilização dos indivíduos torna-se um objetivo essencial para promover um novo tipo de desenvolvimento - o desenvolvimento sustentável” (JACOBI, 2003, p. 193). Com isso, faz parte da formação do cidadão reflexivo e crítico conhecer o que está ao seu redor, principalmente o que se relaciona às questões ambientais, que, por sua vez, estão associadas às questões sociais e à qualidade de vida da população local/global. Desse modo, a educação ambiental pode contribuir para o desenvolvimento de uma consciência ecológica crítica e para uma participação mais ativa dos estudantes na sociedade (UHMANN, 2011).

Chassot (2018) acredita que temos um constante desafio enquanto professores: envolver os estudantes nos problemas, que lhes são mais próximos, relacionados ao ambiente. $\mathrm{O}$ autor explica que vale mais para o estudante separar o lixo em casa, do que discutir sobre os riscos dos derivados de fluorcarbonetos para a camada de ozônio (CHASSOT, 2018). Até porque, relacionando duas categorias emergentes deste estudo, preservar o meio ambiente deve estar presente no cotidiano dos alunos. A partir da 
Edição Especial: I SSAPEC - Simpósio Sul-Americano de Pesquisa em Ensino de Ciências

ISSN: 2595- $4520 \quad$ Vol. 4, n. 32021

sensibilização individual de cada sujeito para com o meio ambiente em que vive é que se pode construir uma sensibilização coletiva que poderá solucionar problemas ambientais em âmbitos mais abrangentes.

Porém, Fracalanza, Amaral e Gouveia (1986) atentam para as maneiras como são trabalhados os problemas ecológicos e destacam dois pontos para discussão e reflexão. $\mathrm{O}$ primeiro refere-se "à excessiva importância atribuída às formas de uso e às reservas mundiais dos recursos naturais" (FRACALANZA; AMARAL; GOUVEIA, 1986, p. 116) que reforçam a visão antropocêntrica de uma natureza que importa apenas se tem utilidade para os seres humanos. O outro diz respeito "ao tratamento meramente científico conferido à ecologia, com destaque para fenômenos naturais que mantêm ou afetam o equilíbrio biológico natural" (FRACALANZA; AMARAL; GOUVEIA, 1986, p. 116).

Esses autores defendem que tal abordagem transmite a mensagem política de que a conservação da natureza depende exclusivamente da sensibilização individual, de cada cidadão, e que o ideal seria abordar o contexto histórico, o tempo presente e o geológico, o funcionamento da natureza e suas transformações. Além disso, questões políticas e econômicas precisam ser discutidas, bem como as sociais, que se interrelacionam com temas como o consumo, por exemplo.

Nesse sentido, Loureiro (2019) destaca diversos aspectos que devem ser considerados para desenvolver a educação ambiental como, por exemplo: compreender e fazer compreender a relação sociedade-natureza; problematizar e entender o contexto em que estamos inseridos (seja local, regional, nacional e/ou mundial); envolver os elementos políticos, sociais e culturais junto aos elementos ambientais, considerando que existem conexões e que eles se inter-relacionam; e considerar que ações pontuais são válidas, mas que a solução está no desenvolvimento em todo o processo educativo.

Loureiro (2019) ainda reforça que ações individuais são importantes, mas que a transformação da sociedade ocorre nas ações coletivas. $\mathrm{O}$ autor aborda a inter-relação entre economia, política, cultura e as questões sociais e ambientais e como precisamos compreender o todo para poder atuar na vida pública de diversas maneiras, como, por exemplo, por meio do voto. Escolher representantes que possuem projetos e propõem mudanças efetivas para a cidade, estado e país em que se vive é um dos principais atos para a transformação da sociedade. Por isso se destaca a importância da criticidade no 
ensino de Ciências.

\subsection{Ciências para ser crítico}

Por fim, a última categoria constituída foi Ciências para ser crítico, que emergiu de três US que foram escritas por três licenciandos.

Para ensinar as pessoas a serem críticas, pesquisar e buscar conhecimento (L4, 2020).

Para que elas possam questionar o mundo em que vivem [...] (L5, 2020).

Moraes e Ramos (1988) salientam que o professor precisa dar-se conta de seu papel e do papel da escola no processo formativo, e, para termos uma sociedade democrática e justa, as pessoas não podem ser preparadas para repetir, se submeter e obedecer cegamente. Com isso, o pensamento crítico promove capacidades que permitem incentivar as pessoas a utilizar "informação e formas de pensar, incluindo o de pensar de forma crítica, para a tomada de decisão esclarecida e racional, para a resolução de problemas e para a participação ativa e responsável numa sociedade democrática" (TENREIRO-VIEIRA; VIEIRA, 2014, p. 8).

Os alunos precisam pesquisar, refletir e analisar para que possam filtrar as informações que lhes são apresentadas e não acreditar em fake news e/ou nas teorias pseudocientíficas que são disseminadas atualmente. Com isso, é preciso preparar os estudantes para o "exercício de uma cidadania, responsável e consciente, mediante o desenvolvimento de uma sólida cultura científica e tecnológica" (GONÇALVES; VIEIRA, 2015, p. 9).

Nesse sentido, Duarte (2018) caracteriza o contexto em que estamos inseridos:

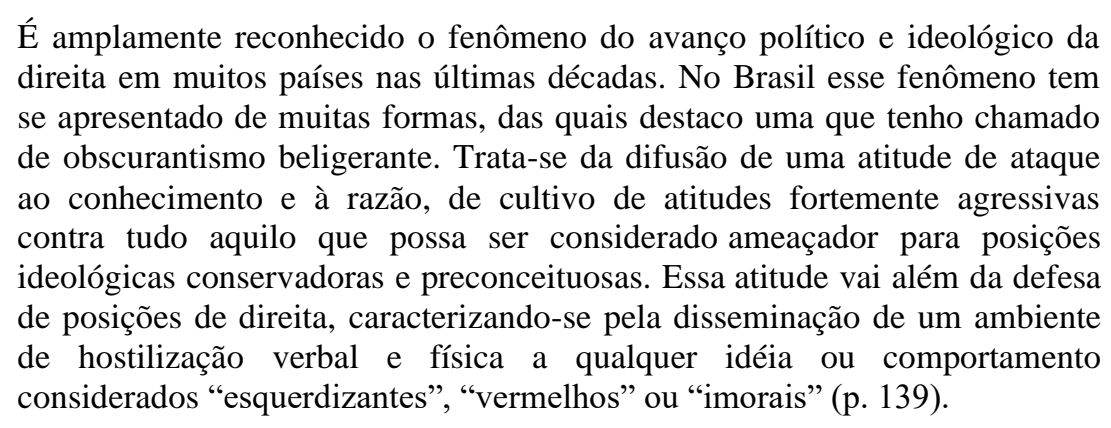

Desse modo, as notícias falsas vêm ganhando espaço e desenvolvendo coletivos que defendem pseudociências e desafiam fatos já estabelecidos, como os terraplanistas, e outros grupos ainda mais preocupantes que ocasionam graves consequências para o 
país, como o movimento antivacina. Assim, o conhecimento científico ensinado nas escolas tem o compromisso de desenvolver uma "concepção de mundo mais coerente e mais objetiva, no qual os sujeitos possam se reconhecer como produto e produtores da sua própria história” (MESSEDER NETO, 2019, p. 18).

Messeder Neto (2019) também destaca a importância da discussão sobre os conceitos de verdade, de conhecimento científico e da natureza da Ciência, para elucidar a história e os contextos de construção desses conhecimentos. Essas questões abrem caminho para outras problematizações, como a relação entre concepção de mundo, Ciência e religião, uma vez que "o que entendemos e valoramos por ser humano, pela nossa relação com a natureza, com as pessoas ao redor e o modo como agimos e fazemos nossas escolhas está vinculada à nossa concepção de mundo" (MESSEDER NETO, 2019, p. 15).

Percebemos que as três categorias estão relacionadas, já que ensinar para a preservação do meio ambiente e para a criticidade influenciam e são influenciadas pelo cotidiano do aluno. Por isso, contextualizar o ensino de Ciências é fundamental para que os estudantes participem ativamente da/na sociedade em que vivem, desenvolvendo-se, assim, como cidadãos críticos e reflexivos que vejam na sociedade as mudanças que precisam ser feitas e que busquem realizá-las.

As categorias emergentes também nos fazem refletir sobre questões da natureza da Ciência e epistemologia e como são abordadas em sala de aula. Gil-Pérez e colaboradores (2001) apresentam visões deformadas que constituem os currículos de Ciências e defendem a superação da formação de cientistas nas escolas, abrindo espaços para a formação de cidadãos que consigam articular os conhecimentos científicos às questões sociais, ambientais e culturais.

Corroborando com Macêdo e Kalhil (2015, p. 58), “é imprescindível uma formação científica cidadã e crítica para que os estudantes de hoje sejam formados para intervir na complexidade que lhes é imposta pela sociedade", tornando-se, assim, sujeitos partícipes das decisões da sociedade, que compreendam as dimensões sociais, ambientais, históricas e culturais do contexto em que se inserem.

Após a análise e discussão das escritas narrativas pelos licenciandos, identificamos três elementos que se destacam: o cotidiano, o meio ambiente e a criticidade. De acordo com os licenciandos, esses são os principais motivos que um 
Edição Especial: I SSAPEC - Simpósio Sul-Americano de Pesquisa em Ensino de Ciências

ISSN: 2595-4520 Vol. 4, n. 32021

docente deve ter ao ensinar Ciências. Moraes e Ramos (1988) defendem que, para compreender o porquê de ensinar Ciências, precisamos nos perguntar que sujeito queremos formar. Por isso, os questionamentos precisam ser constantemente refletidos na formação inicial e, posteriormente, na formação continuada, no decorrer do desenvolvimento profissional.

O licenciando, ao escrever e refletir sobre essas questões, constrói e reconstrói suas concepções acerca das finalidades e dos objetivos do ensino de Ciências. Esse processo é importante, pois pensar no "por que?" e no "para que?" ensinar Ciências define os seus objetivos enquanto professor e norteia o seu planejamento.

Essas duas questões antecedem e direcionam a escolha dos conteúdos (o que ensinar?), as metodologias (como ensinar?), os recursos didáticos (com o que ensinar?) (MORAES; RAMOS, 1988). Buscando "respostas" para esses questionamentos e refletindo sobre elas, o professor entende melhor o seu papel, o da escola e o do aluno na sociedade (CARVALHO, 2004).

\section{CONCLUSÃO}

A partir da IFAC proposta, foi possível perceber que as escritas narrativas dos licenciandos são muito importantes para os processos de sistematização de compreensões e reflexões, além de desenvolver suas produções autorais. Para além das nossas análises e reflexões enquanto investigadoras ativas, a IFAC também apresentou momentos de leitura e reflexão, além de diálogos formativos experienciados nas aulas da PeCC III.

No cenário reflexivo foi possível, pela ATD, identificar as diferentes finalidades e objetivos do ensino de Ciências de acordo com os licenciandos, relacionando essas concepções com as de teóricos que escreveram sobre isso. Destacamos nesta análise, através das escritas narrativas dos licenciandos, três categorias que apresentam quais os motivos para ensinar Ciências: Ciências e cotidiano; Ciências para preservar o meio ambiente; e Ciências para ser crítico. Ficou evidente que as escritas narrativas conversam com os referenciais teóricos, e podem influenciar as futuras práticas docentes dos envolvidos.

Percebemos o quanto foi importante para os licenciandos refletirem sobre o ensino de Ciências, a postura crítica assumida possibilitou emergir suas reflexões no 
intuito de produzir sentidos às futuras práticas. Nesse sentido, demonstramos como o processo de IFAC potencializou a formação inicial de professores por meio de escritas narrativas, diálogos formativos e demais reflexões que ocorreram durante a PeCC III.

Não obstante, acreditamos ter sido relevante assumir, pela IFAC, o processo de formação inicial voltado às práticas de ensino, pois esse processo permitiu aos licenciandos enunciar, nas escritas narrativas, suas compreensões, além de dialogar com os pressupostos teóricos e metodológicos do ensino com os quais têm contato na licenciatura. Tais compreensões permeiam sua constituição docente.

\section{REFERÊNCIAS}

ALARCÃO, I. Professores reflexivos em uma escola reflexiva. 8. ed. São Paulo: Cortez, 2011.

BOSZKO, C.; ROSA, C. T. W. Diários Reflexivos: definições e referenciais norteadores. Revista Insignare Scientia, v. 3, p. 18, 2020.

BREMM, D.; GÜLLICH, R. Sistematização de experiências: conceito e referências para formação de professores de Ciências. Revista REAMEC, Cuiabá, v. 8, n. 3, p. 553-575, set-dez 2020.

CARVAlHO, A. M. P (org). Ensino de Ciências: Unindo a Pesquisa e a Prática. São Paulo: Cengage Learning, 2004.

CHASSOT, A. Alfabetização científica: questões e desafios para a educação. 8. ed. Ijuí: Editora Unijuí, 2018.

CHAVES, S. N. Por que ensinar ciências para as novas gerações? Uma questão central para a formação docente. Contexto e Educação, Editora Unijuí, v.22, n. 77, p. 11-24, jan./jun. 2007.

CHAVES, S. N. Reencantar a ciência, reinventar a docência. São Paulo: Editora Livraria da Física, 2013.

CONTRERAS, J. D. La investigación en la acción. Cuadernos de Pedagogia, Madrid: Morata, n. 224, p. 7-31, abr. 1994.

DELIZOICOV, D.; ANGOTTI, J. A. Metodologia do ensino de ciências. São Paulo: Cortez, 1994.

DUARTE, N. O currículo em tempos de obscurantismo beligerante. Revista Espaço do Currículo, João Pessoa, v. 2, n. 2, p. 139-145, mai/ago, 2018.

ELLIOTT, J. La investigación-acción en educación. Madrid: Ediciones Morata, 1990.

EMMEL, R. O currículo e o livro didático da educação básica: contribuições para a formação do Licenciando em Ciências Biológicas. 2015. 153 p. Tese (Pós-Graduação em Educação nas Ciências) - Universidade Regional do Noroeste do Estado do Rio Grande do Sul, Ijuí, 2015.

FRACALANZA, H.; AMARAL, I. A.; GOUVEIA, M. S. F. O ensino de ciências no primeiro grau. São Paulo: Atual, 1986. 
GASTAL, M. L. A.; AVANZI, M. R. Saber da experiência e narrativas autobiográficas na formação inicial de professores de biologia. Ciência e Educação, Bauru, v. 21, n. 1, p. 149-158, 2015.

GIANOTTO, D. E. P. Professores de Ciências: o diário de aula como estratégia de reflexão na formação inicial. In: MEGLHIORATTI, F. A.; OLIVEIRA, A. L.; FERRAZ, D. F. (orgs). Reflexões sobre a formação de professores no ensino de Ciências. Cascavel: EDUNIOESTE, 2012, p. 13-36.

GIL-PÉREZ, D.; MONTORO, I. F.; ALÍS, J. C.; CACHAPUZ, A.; PRAIA, J. Para uma imagem não deformada do trabalho científico. Ciência e Educação, v.7, n.2, p.125-153, 2001.

GONÇALVES, E.; VIEIRA, R. M. Aprender Ciências e desenvolver o pensamento crítico: percursos educativos no $1^{\circ}$ ciclo do Ensino Básico. Indagatio didáctica, v. $7, \mathrm{n}$. 1, p. 7-24, jul./2015.

GÜLLICH, R. I. C. O livro didático, o professor e o ensino de ciências: um processo de investigação-formação-ação. 2012. 263 p. Tese (Pós-Graduação em Educação nas Ciências) - Universidade Regional do Noroeste do Estado do Rio Grande do Sul, Ijuí, 2012.

JACOBI, P. Educação Ambiental, cidadania e sustentabilidade. Cadernos de Pesquisa, n. 118, p. 189-205, mar./2003.

KATO, D. S.; KAWASAKI, C. S. As concepções de contextualização do ensino em documentos curriculares oficiais e de professores de Ciências. Ciência e Educação, v. 17, n. 1, p. 35-50, 2011.

LOUREIRO, C. F. B. Educação ambiental: questões de vida. São Paulo: Cortez, 2019.

LÜDKE, M.; ANDRÉ, M. E. D. A. Pesquisa em educação: abordagens qualitativas. São Paulo: EPU, 1986.

LUNARDI, L.; EMMEL, R. As metodologias de ensino dos professores de Ciências e Biologia em formação inicial: analisando as espirais reflexivas nos processos de investigação-formação-ação. In: LEITE, F. A.; EMMEL, R.; COLPO, C. C. Interfaces em pesquisa no Ensino de Ciências. 1. Ed. Bagé, RS: Faith, 2020a.

LUNARDI, L.; EMMEL, R. Reminiscências de licenciandos em Ciências Biológicas sobre o ensino de Ciências na Educação Básica. Práxis Educacional, v. 16, n. 43, p. 472-493, 2020b.

MACÊDO, F. C. S.; KALHIL, J. B. Tecnologias digitais computadorizadas no processo de ensino-aprendizagem de ciências. In.: GONÇALVES, T. V. O.; MACÊDO, F. S. C.; SOUZA, F. L. (org). Educação em ciências e matemáticas: debates contemporâneos sobre ensino e formação de professores. Porto Alegre: Penso, 2015.

MESSEDER NETO, H. S. A divulgação científica em tempos de obscurantismo e de fake news: contribuições histórico-críticas. In: ROCHA, M. B.; OLIVEIRA, R. D. V. L. (org). Divulgação científica: textos e contextos. São Paulo: Editora Livraria da Física, 2019.

MORAES, R.; GALIAZZI, M. C. Análise textual discursiva. 3 ed. Ijuí: Editora Unijuí, 2016. 
MORAES, R.; RAMOS, M. G. Construindo o conhecimento: uma abordagem para o ensino de Ciências. Porto Alegre: SAGRA, 1988.

PORLÁN, R.; MARTÍN, J. El diário del professor: un recurso para investigación en el aula. Diáda: Sevilla, 1997.

RADETZKE, F. S. A docência no ensino superior e a formação continuada dos professores formadores da área de Ciências da Natureza e suas Tecnologias. 2020. Dissertação (Pós-Graduação em Ensino de Ciências) - Universidade Federal da Fronteira Sul, Cerro Largo, 2020.

SELLES, S. E.; FERREIRA, M. S. Disciplina escolar Biologia: entre a retórica unificadora e as questões sociais. In: MARANDINO, M.; SELLES, S. E.; FERREIRA, M. S.; AMORIM, A. C. (org.) Ensino de Biologia: conhecimentos e valores em disputa. Niterói: Eduff, 2005.

TENREIRO-VIEIRA, C.; VIEIRA, R. M. Construindo práticas didático-pedagógicas promotoras da literacia científica e do pensamento crítico. 2. ed. Madrid: Organização dos Estados Ibero-americanos: Iberciencia, 2014.

UHMANN, R. I. M. Estratégias de Ensino e Interações em aulas de Física e Química no Ensino Médio com foco na Educação Ambiental. 2011. Dissertação (Pós-Graduação em Educação nas Ciências) - Universidade Regional do Noroeste do Estado do Rio Grande do Sul, Ijuí, 2011.

ZEICHNER, K. M. Uma análise crítica sobre a "reflexão" como conceito estruturante na formação docente. Educação e Sociedade, Campinas, v. 29, n. 103, p. 535-554, maio/ago. 2008. 